\title{
ARTICLE
}

\section{Geochemical evaluation of land use at a medieval harbor site in Masuda City, Chugoku region, Japan}

\author{
Dalai Banzragch ${ }^{* 1}$, Hiroaki Ishiga ${ }^{2}$ and Damdinpurev Nasandulam ${ }^{1}$ \\ ${ }^{1}$ School of Agroecology, Mongolian University of Life Sciences, Ulaanbaatar, Mongolia \\ ${ }^{2}$ Department of Geoscience, Shimane University, Matsue, Japan
}

ARTICLE INFO: Received: 20 Jun, 2019; Accepted: 12 Dec, 2019

\begin{abstract}
A large-scale Medieval harbor site has been recently discovered at Nakazu-Higashihara in Masuda City, Chugoku region, Japan. The Medieval harbor site is divided into north and south areas. The concentration of 22 elements in soil samples from the north of the harbor site was determined in order to identify the geochemical signatures of the Medieval harbor site. The evidence described in the north area is an example of identification of both natural and anthropogenic processes that lead to geochemical variations within the archaeological soils. The north area of the site contains silt and sandy soils characterized by highest concentration of $\mathrm{Zr}$ and relatively low levels of most other elements (except for Sr and TS). Negative or weak positive correlations between $\mathrm{TiO}_{2}$ and $\mathrm{MnO}$, and $\mathrm{CaO}$ and $\mathrm{P}_{2} \mathrm{O}_{5}$ in the north area indicate that this association of elements represents an ancient anthropogenic signature, especially related to residential sites in all soil types. Correlation between $\mathrm{TiO}_{2}$ and $\mathrm{Ni}, \mathrm{Y}, \mathrm{Nb}, \mathrm{Zr}$, Th, and $\mathrm{Fe}_{2} \mathrm{O}_{3}$ did not reflect the anthropogenic history. However, these elements and their ratios can be used to identify sources, as well as to establish baseline concentration of other elements which are influenced by anthropogenic and detrital inputs.
\end{abstract}

Keywords: soil; geochemistry; archaeological site; PCA;

\section{INTRODUCTION}

Geochemical analysis of soils is now a significant additional tool that can be useful for archaeological exploration and site survey, as well as for reconstruction of land use histories $[1,2,3,4]$. Previous studies of soils and sediments altered by humans have shown that specific activities leave characteristic chemical signatures on prepared earthen surfaces $[1,2,5,6,7]$. Examples of elements associated with human activities include calcium and strontium with areas of organic waste disposal [2], mercury and lead associated with craft production [3], and phosphorus together with high concentration of magnesium and zinc as evidence of faecal material and wood ash residues [1]. However, geochemical variations of archaeological soils cannot be fully related to ancient human activity [4]. Local geology, geomorphic setting, and soil formation processes also contribute to these 
variations: for example, parent material and grain size fractionation during transport and deposition may also strongly influence the bulk geochemical composition of archaeological soils $[8,4]$. The complexity of both human and natural processes may not be identified by signatures from single chemical elements alone. However, combination of many different elements, as can be produced by multielement soil analysis, can provide additional information on the chemical signatures.

The western coast of southwest Japan lies close to the Southeast Asian continent, and thus has been an important place for exchange of culture, people and trade. Recently excavated medieval harbor known as the Nakazu sites in Masuda City, Shimane Prefecture, Chugoku region, Southwest Japan is one site of such exchanges. The Nakazu Higashihara harbor site was well located for ships sailing along the marine coast, especially for conducting trade with mainland China and the Korean Peninsula. Present archaeological investigations have identified over 800 construction pits, blacksmith hearths and harbor structures, along with ceramic fragments originating both from within Japan and from Asia (China, Korea, Vietnam and Thailand) [9]. Investigations of these ceramics have established that the Masuda Clan (a local "Samurai" dynasty) operated a prosperous maritime trade network from this harbor site in East Asia, which brought significant wealth to the area [10]. The Masuda Clan originated from the Fujiwara Clan in the late Heian Period (late $12^{\text {th }}$ century), and took the name of the locality. Twenty descendants were recorded in the genealogy line [9]. The long history of the clan thus suggests that the harbor site could have received a considerable volume of ancient anthropogenic matter. The Masuda Clan was the frontier of a sophisticated culture, which formed the foundation of the development of the western Chugoku region. The clan constructed the Miyake Odoi (a fort), residences, and Nanao castle, showing the expansion of their power in the region [9].

\section{Study area}

The Nakazu Higashihara and Nakazu Nishihara sites are parts of a larger single archaeological site, which was established in the 12 th century, operating as a trading hub for the Masuda clan. The sites were constructed at the estuary of the Takatsu and Masuda rivers in western Shimane Prefecture (the western part of Iwami-nokuni in ancient terminology), facing the Sea of Japan (Fig. 1). At present, the sites are situated in the northern part of the river mouth delta (Fig. 1), and sand dunes have developed along their northern side. It is well known that the mechanism of Japanese coastal plain formation was strongly related to sea level changes following the last glaciation [11]. At the early Holocene stage (about 10 kyrs BP, called Jomon Period), sea level had gradually risen due to warming climate after the last glaciation $[11,12,13]$. The site was thus under shallow marine conditions, as shown by geologic examination $[14,15]$ and the remains of fishery [14]. A sand bar built from sands transported by the Takastu and Masuda rivers formed along the sides facing the ocean [15]. The present coastal plain formed after minor regression between the years 3500 and $4660 \mathrm{yr}$ BP (in the Yayoi Period) related to a cooling mode, and rice agriculture was introduced, as indicated by pollen analysis [16] and archaeological examinations [9]. The Masuda plain has been used for cultivation from this period onward. The sand bar built from clastic material transported by the rivers and the dunes built back on the inner side of the coast dominated in the late Yayoi Period. The estuary of the Masuda rivers is thought to have been semi-closed due to the development of bars, resulting in the formation of a shallow lagoon which was partly connected to the sea [15]. The site was thus well located for ships sailing along the coast, especially for conducting trade with mainland China and the Korean peninsula $[17,9]$. However, in the 16 th century the harbor function shifted upriver to Imaichi, due to marine regression and sedimentation [15]. 


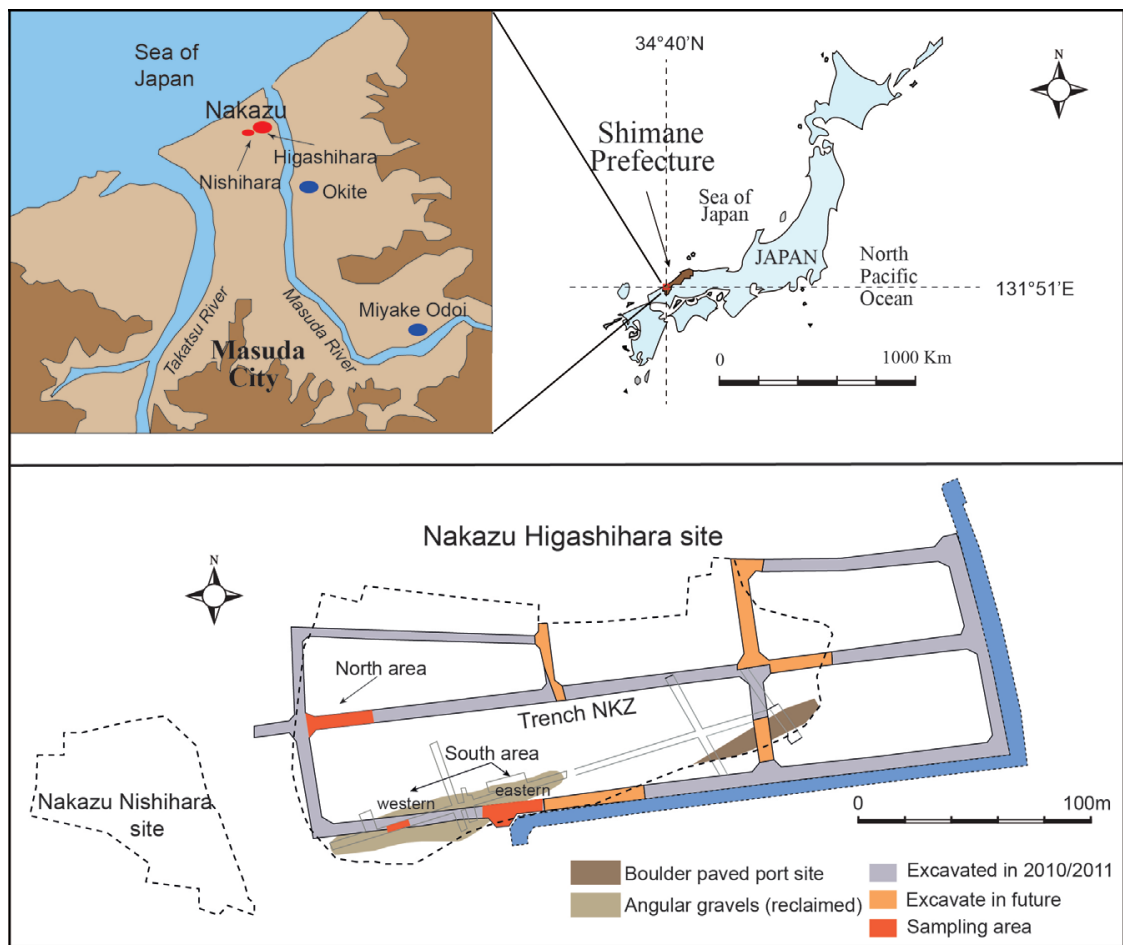

Figure 1. Location map of the study area and sampling points at the Nakazu Higashihara site, Masuda City, Chugoku region, Japan

The Nakazu Higashihara site is located east to the Nakazu Nishihara site (Fig. 1), and contains many remains of building pillars and ceramics, blacksmith furnaces, fire pits, charcoals and graves. The imported ceramics include Celadon, white porcelain, and blue and white wares originating from China, Thai, Vietnam and the Korea Peninsula. These imported ceramics are useful for identifying the age of places in the site, which range from the late $12^{\text {th }}$ century to early $17^{\text {th }}$ century. Among them, ceramics pertaining to the late $14^{\text {th }}$ to early $17^{\text {th }}$ century are dominant, from among which a number of imported ceramics were found. The maximum number (662) recovered so far appertain to the late $15^{\text {th }}$ to early-middle $16^{\text {th }}$ centuries. This is suggestive of growing trade through to the $17^{\text {th }}$ century. After that, the style of ceramic fragments changed to the Higo ceramics of Kyushu, the western neighbor of Chugoku region, indicating development of production of chinaware in Japan. It is said that manufacturing technology was also introduced at this time, and was further developed in northern Kyushu [9].

The most important finding to note in the southern part (south area) of the Medieval harbor site is a $40 \mathrm{~m}$-long boulder pavement of the port, built on fine sediments (mainly clay) (Fig. 1) [18]. The pavement consists of rounded cobbles and boulders. Its position along the shoreline fronting the lagoon suggests the pavement may have been a boat landing and/ or a dock for boat repair [9]. Recent excavation in the northern part (north area) of the site has mainly revealed remains of building pillars and pottery fragments. This particular area is embedded in silt and sandy soils, and was bordered by sand dunes on its seaward side. The Masuda clan shifted to the Susa area in the east of the middle Iwami district after 1600, and thus their record disappeared in Masuda City [9]. 


\section{MATERIALS AND METHODS}

\section{Sample collection}

Soil samples collected from the surface of archaeological horizon (archaeological floor samples) are indicated as prehistoric occupation in Medieval period. The exposed surface (about 2 3 $\mathrm{mm}$ thickness) of the archaeological horizon was first peeled off to avoid contamination by foot traffic and metal tools used during the archaeological survey. Samples about 3 5 $\mathrm{mm}$ in thickness were then taken from the archaeological horizon. Samples collected from the horizons which were deposited after prehistoric occupation floor are referred to as topsoil samples (non-archaeological samples). Topsoil samples were examined in order to identify the geochemical signals between modern and archaeological soils.

It is expected that these two deposits should differ geochemically, as a result of natural processes and anthropogenic activities at different periods.

In July 2012, 26 soil samples were collected from the north area of the harbor site which is embedded in silt and sandy soils (Fig 2). Eighteen archaeological floor samples were taken from a horizontal transect across the surface of archaeological horizon, while eight topsoil samples were collected from the nonarchaeological horizon (A point).

The soil samples weighing about $200 \mathrm{~g}$ each were packed in zip-lock bags and stored in a cooler box at $4^{\circ} \mathrm{C}$ for transportation.

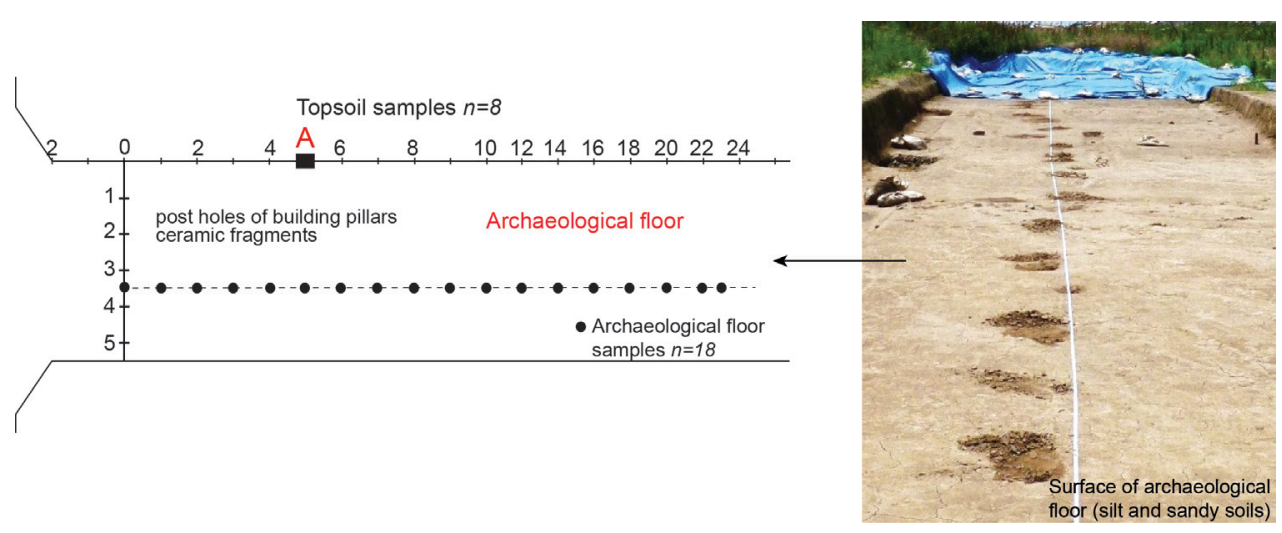

Figure 2. Sampling points: North area of the Nakazu Higashihara site, Masuda

\section{Analytical procedures}

Abundance of selected major elements $\left(\mathrm{TiO}_{2}, \mathrm{Fe}_{2} \mathrm{O}_{3} *\right.$ [total iron expressed as $\mathrm{Fe}_{2} \mathrm{O}_{3}$ ], $\mathrm{MnO}, \mathrm{CaO}$ and $\mathrm{P}_{2} \mathrm{O}_{5}$ ) and trace elements $\mathrm{As}$, $\mathrm{Pb}, \mathrm{Zn}, \mathrm{Cu}, \mathrm{Ni}, \mathrm{Cr}, \mathrm{V}, \mathrm{Sr}, \mathrm{Y}, \mathrm{Nb}, \mathrm{Zr}$, Th, Sc, $\mathrm{F}, \mathrm{Br}$, I and TS (total sulfur) in the soils were determined by X-ray fluorescence analysis (XRF) in the Department of Geoscience, Shimane University, using a Rigaku Co. Ltd. RIX-2000 spectrometer.

After removal of gravels, roots, and other plant material, approximately $50 \mathrm{~g}$ of each sample was dried in an oven at $160^{\circ} \mathrm{C}$ for 48 hrs to remove weakly-bound volatiles. The dried samples were then ground for $20 \mathrm{~min}$ in an automatic agate pestle and mortar grinder.

The XRF analyssis was made on pressed powder briquettes (about $5 \mathrm{~g}$ sample compressed by a force of $200 \mathrm{kN}$ for $60 \mathrm{~s}$ ), following the method of Ogasawara [19]. Average errors for all elements are less than $\pm 10 \%$ relative. Analytical results for GSJ standard JS1-1 were acceptable compared to the proposed values of Imai et al. [20]. 


\section{RESULTS AND DISCUSSION}

\section{Geochemical characteristics of}

archaeological and non-archaeological soils

Average geochemical compositions and ranges of topsoil and archaeological floor samples from north area of the harbor site are given in Table 1. Average data for four modern stream sediments from the Takatsu River [21] are also included as a measure of the general background concentrations that can be expected for each element. Geochemical variations between topsoil and archaeological floor samples are greatest in the southern area [18], and less in the northern area of the harbor site (Figs. 3, 5 and 6). However, significant compositional differences are seen between data for archaeological floor samples from the north and south areas of the harbor site. Archaeological floor samples from the north are characterized by highest concentrations of $\mathrm{Zr}$ ranging from 143-201 ppm with an average value of 181, and relatively low levels of most other elements, except for $\mathrm{Sr}$ and TS. In contrast, anthropogenically significant elements such as $\mathrm{As}, \mathrm{Pb}, \mathrm{Zn}, \mathrm{Cu}, \mathrm{Ni}, \mathrm{Sc}, \mathrm{F}$, $\mathrm{CaO}, \mathrm{MnO}, \mathrm{Fe}_{2} \mathrm{O}_{3}$ and $\mathrm{P}_{2} \mathrm{O}_{5}$ are much more abundant in the south area, which is recognized as a production district of the harbor site [18]. Considering the entire dataset, abundance of several elements such as $\mathrm{Cr}, \mathrm{V}, \mathrm{Y}, \mathrm{Nb}$, Th and $\mathrm{TiO}_{2}$, including halogens (except for $\mathrm{F}$ ) do not differ greatly between the two areas.

Table 1. Mean and range of elemental concentration of topsoil and archaeological floor samples from the northern area of the Nakazu Higashihara site, Masuda City, Chugoku region, Japan

\begin{tabular}{|c|c|c|c|c|c|}
\hline \multirow{4}{*}{ Elements } & \multicolumn{4}{|c|}{ North area } & \multirow{3}{*}{$\begin{array}{c}{ }^{*} \text { Takatsu } \mathrm{R} \\
\mathrm{n}=4\end{array}$} \\
\hline & \multicolumn{2}{|c|}{ Topsoil } & \multicolumn{2}{|c|}{ Archaeological floor } & \\
\hline & \multicolumn{2}{|c|}{$\mathrm{n}=8$} & \multicolumn{2}{|c|}{$\mathrm{n}=18$} & \\
\hline & Mean & Range & Mean & Range & Mean \\
\hline As & 40 & $28-60$ & 42 & $27-56$ & 26 \\
\hline $\mathrm{Pb}$ & 36 & $32-44$ & 32 & $26-39$ & 19 \\
\hline $\mathrm{Zn}$ & 119 & $105-132$ & 113 & $79-128$ & 73 \\
\hline $\mathrm{Cu}$ & 39 & $35-42$ & 33 & $21-41$ & 19 \\
\hline $\mathrm{Ni}$ & 24 & $16-29$ & 25 & $16-31$ & 13 \\
\hline $\mathrm{Cr}$ & 51 & $41-70$ & 54 & $37-67$ & 34 \\
\hline V & 110 & $98-124$ & 114 & $74-136$ & 67 \\
\hline $\mathrm{Sr}$ & 110 & $104-113$ & 106 & $99-124$ & 108 \\
\hline $\mathrm{Y}$ & 31 & $28-33$ & 32 & $28-33$ & 23 \\
\hline $\mathrm{Nb}$ & 12 & $11-12$ & 11 & $9-12$ & 7 \\
\hline $\mathrm{Zr}$ & 191 & $185-198$ & 181 & $143-201$ & 129 \\
\hline Th & 13 & $11-15$ & 13 & $9-16$ & 9 \\
\hline $\mathrm{Sc}$ & 6 & $5-8$ & 7 & $4-8$ & 6 \\
\hline $\mathrm{F}$ & 76 & $0-261$ & 89 & $0-261$ & \\
\hline $\mathrm{Br}$ & 4 & $3-4$ & 4 & $0-5$ & 1 \\
\hline I & 19 & $17-20$ & 24 & $0-31$ & 21 \\
\hline TS & 449 & $429-488$ & 441 & $397-492$ & 271 \\
\hline $\mathrm{TiO}_{2}$ & 0.61 & $0.54-0.65$ & 0.61 & $0.43-0.68$ & 0.35 \\
\hline $\mathrm{CaO}$ & 0.95 & $0.90-0.98$ & 0.94 & $0.89-0.99$ & 0.99 \\
\hline $\mathrm{MnO}$ & 0.28 & $0.17-0.70$ & 0.22 & $0.14-0.56$ & 0.09 \\
\hline $\mathrm{Fe}_{2} \mathrm{O}_{3}$ & 5.31 & 4.14-6.56 & 5.42 & $3.84-6.42$ & 3.84 \\
\hline $\mathrm{P}_{2} \mathrm{O}_{5}$ & 0.33 & $0.23-0.65$ & 0.25 & $0.18-0.33$ & 0.08 \\
\hline $\mathrm{Th} / \mathrm{Sc}$ & 2.06 & $1.75-2.22$ & 1.97 & $1.62-2.42$ & 1.52 \\
\hline $\mathrm{Zr} / \mathrm{Sc}$ & 30.76 & 25.43-35.28 & 28.14 & $23.15-39.28$ & 21.80 \\
\hline
\end{tabular}

*Takatsu River sediment data from Hodoki et al. [21] 
Inter-element relationships in

archaeological soils

Principal component analysis (PCA) using MINITAB 14 software was used for the classification of archaeological floor samples newly collected from the north and previously published data [18] of south areas of the harbor site. The first two principal components account for 63.1 percent of the total data variance from the correlation matrix. The score plot (Fig. 3a) is used for the classification of archaeological floor samples, and a loading plot (Fig. 3b) is used to identify the variability of multi-elements and to define their possible sources. Sample scores on the first two components show that archaeological floor samples are divided into two main groups according to their location (Fig. 3a). These compositional differences could be associated with the individual prehistoric human activities carried out in each area. Or soil textures and parent material variations may have played a role in the differing geochemical compositions see in the two areas which are embedded in different soil types. Multi-elements scatter within three sectors of the loading plot, and several elemental groups are identified (Fig. 3b). Elements in these groups have similar geochemical behavior that suggests derivation from specific sources. Chromium, $\mathrm{V}, \mathrm{Nb}, \mathrm{Th}$ and $\mathrm{Ti}$ are grouped together, and are characterized by high positive PC1 loadings. These elements are generally regarded as conservative lithogenic elements, and hence, these associations are mainly related to natural sources. Strontium, I, TS and Zr form another separate group with high positive PC1 and PC2 loadings. Zirconium s mainly occurs in sand to silt fractions, due to the enrichment of heavy minerals (notably zircon) that are concentrated by mechanical sorting [22]. This group of elements, to all likelihood, isassociated with the texture of the soils, and hence, is mainly of natural origin. Fluoride, $\mathrm{CaO}$ and $\mathrm{P}_{2} \mathrm{O}_{5}$ showed negative loadings for both PC1 and PC2 (Fig. $3 \mathrm{~b}$ ). Calcium and $\mathrm{P}$ (including fluorine ions) are well known as major components of tooth and bone minerals.

Furthermore, $\mathrm{P}$ is generally regarded as an anthropogenic element in both ancient and modern activity areas, because of the addition of plant and animal residues, bone, urine, firing and cooking processes [23,24]. The close relationships between $\mathrm{F}, \mathrm{CaO}$ and $\mathrm{P}_{2} \mathrm{O}_{5}$ thus reflect a similarity in source, associated with deposition of occupation wastes. Many other elements $\mathrm{As}, \mathrm{Pb}, \mathrm{Zn}, \mathrm{Cu}, \mathrm{Ni}, \mathrm{Sc}, \mathrm{Y}, \mathrm{Br}$, $\mathrm{MnO}$ and $\mathrm{Fe}_{2} \mathrm{O}_{3}$ scatter on the loading plot, with positive PC1 and negative PC2 loadings (Fig. 3b). These elements (except for $\mathrm{Y}$ and $\mathrm{Br}$ ) generally show highest concentrations in archaeological floor samples from the south area (Fig. 6). These enrichments seem to be related to ancient anthropogenic practices at the harbor site. 

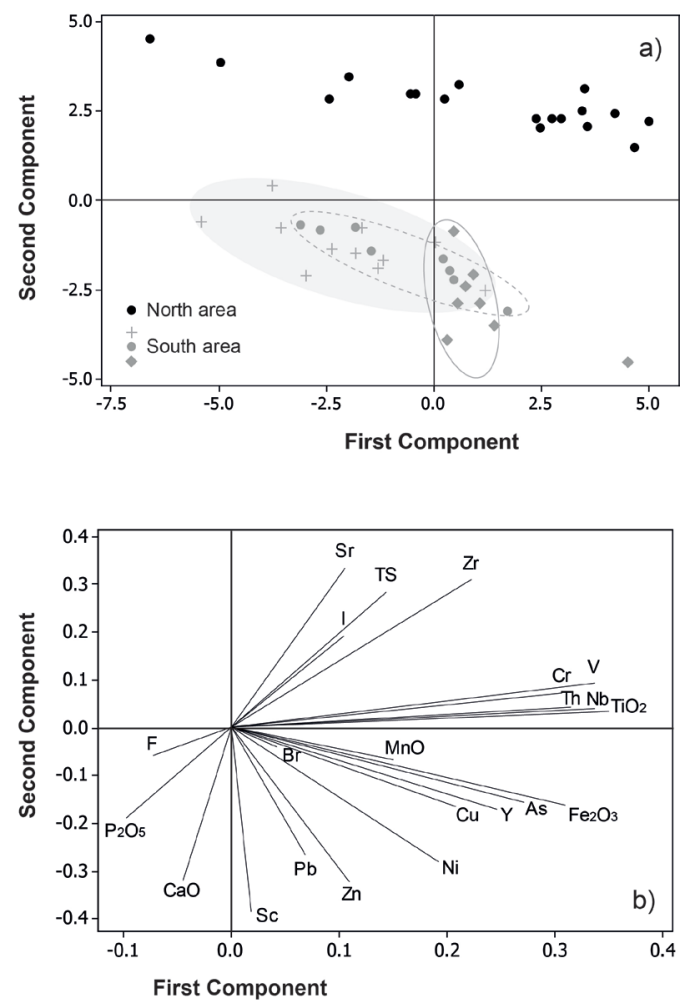

Figure 3. Results of Principal Component Analysis (PCA) of geochemical data of archaeological floor samples from the northern and southern areas of the Nakazu Higashihara site. (a) Sample scores;

(b) Principal component loadings. South area [18] symbols: plus - fire pit and charcoal area; circle - building pillar area; diamond - blacksmith furnace area

\section{Anthropogenic and detrital influences on archaeological soils}

Average abundance of most analyzed elements are lowest in the north area, relative to the south (Fig. 5 and 6). This suggests that the north area was less affected by prehistoric human activities. Alternatively, soil textures and parent material may have played a role in the differing elemental concentrations seen in two areas, as they contain different soil types. Therefore, comparison with values for sediments carried by the present-day Takatsu River [21] was made, based on immobile trace element ratios. The Takatsu River data could be representing the background concentration of elements given its significance in local soil-forming processes at the harbor site. Consequently, elemental ratios $\left(\mathrm{TiO}_{2}-\right.$ element) were used here to evaluate potential anthropogenic and natural influences on the archaeological soils.

Geochemical studies have often used $\mathrm{Al}_{2} \mathrm{O}_{3}, \mathrm{Fe}_{2} \mathrm{O}_{3} *$ and $\mathrm{TiO}_{2}$ contents as proxies to define sediment sources and to evaluate grain size effects [25,26,27]. Titanium is generally regarded as a conservative lithogenic element that is abundant in clays. Elements that show strong correlation with $\mathrm{TiO}_{2}$ should therefore only reflect inputs of natural detrital. If no such correlations exist, additional natural or anthropogenic processes may have contributed to element loadings.

Considering the data of the north and previously published data [18] of south areas, no geochemical differences were found between $\mathrm{TiO}_{2}$ and $\mathrm{V}, \mathrm{Cr}$, Th and $\mathrm{Nb}$ (Fig. 5). These elements are good indicators of provenance, as their mobility in surface 


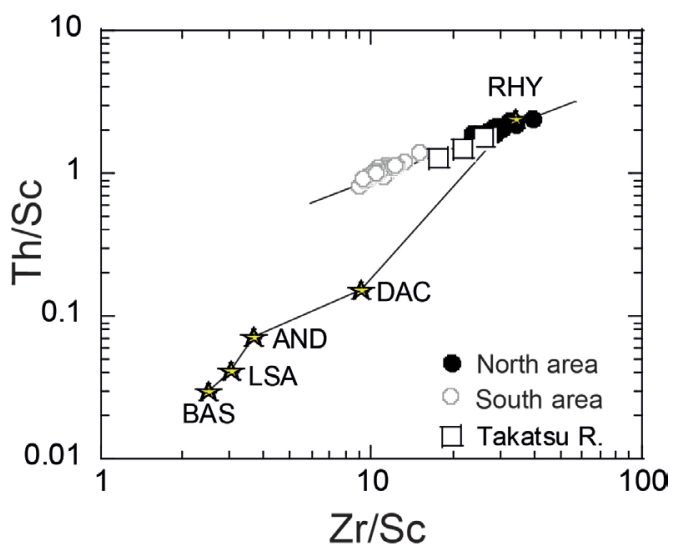

Figure 4. Immobile trace elements Th/Sc-Zr/Sc plot [30] for archaeological floor samples from the northern and southern area of the Nakazu Higashihara site. Stars are typical values for basalt (BAS), lowsilica andesite (LSA), andesite (AND), dacite (DAC) and rhyolite (RHY), showing the trend of magmatic evolution (as plotted by Roser \& Korsch [31]). Present-day Takatsu River sediment samples represent local background values (data from Hodoki et al. [21])

conditions is limited. They show strong positive correlations with $\mathrm{TiO}_{2}$, and all samples in both areas lie on single linear trends originating from the background values in Takatsu River sediments (Figs. 5a-d). This means that during the relatively short time frame of the Medieval Nakazu Higashihara harbor site, little change in source composition occurred during the period of deposition. This interpretation is reinforced by an immobile element $\mathrm{Th} / \mathrm{Sc}-\mathrm{Zr} /$ Sc ratio plot (Fig. 4). Both the north and south areas show high $\mathrm{Th} / \mathrm{Sc}$ and $\mathrm{Zr} / \mathrm{Sc}$ ratios, clearly indicating that they were derived from the same felsic parent material (provenance), and that no change in source occurred. Somewhat higher ratios occur in samples from the north area, suggesting enrichment of zircon.

Samples from the north area, which is embedded in silt and sandy soils, contained high concentration of $\mathrm{Zr}$ (Fig. 5e) and relatively low abundance of most other elements analyzed (except Sr and TS) (Fig. 5 and 6). This geochemical variation between the two areas may be associated with the proportion of silt and clay, as clay particles have a high capacity for adsorbing or retaining trace metals. On the other hand, lower concentration of elements in the north may simply be because that area was not affected by manufacturing activities. This geochemical evidence coincides well with archaeological information, such as the numerous post holes of building pillars and ceramic fragments found in the north area. This may indicate that the north was mainly a 'residential area' (living area) of the site. Traditionally, human settlements have developed in mixed-use patterns. These features and results suggest that land use management in Medieval Japan was developed and had already introduced separation of different functions such as manufacturing and residential areas. However, combination of functions at the south area is much more likely to have been a matter of convenience, with manufacturing near the port requiring less transport [18].

$\mathrm{Ni}$ and $\mathrm{Fe}_{2} \mathrm{O}_{3}$ are strongly correlated with $\mathrm{TiO}_{2}$ in both areas (Figs. $5 \mathrm{~g}$ and $\mathrm{h}$ ), indicating they are concentrated in clay minerals and fine-grained heavy minerals, and hence are mainly of natural origin [26].

From a geochemical viewpoint, the residential area (north area) was less affected by ancient anthropogenic activities compared with the production area in the south. 

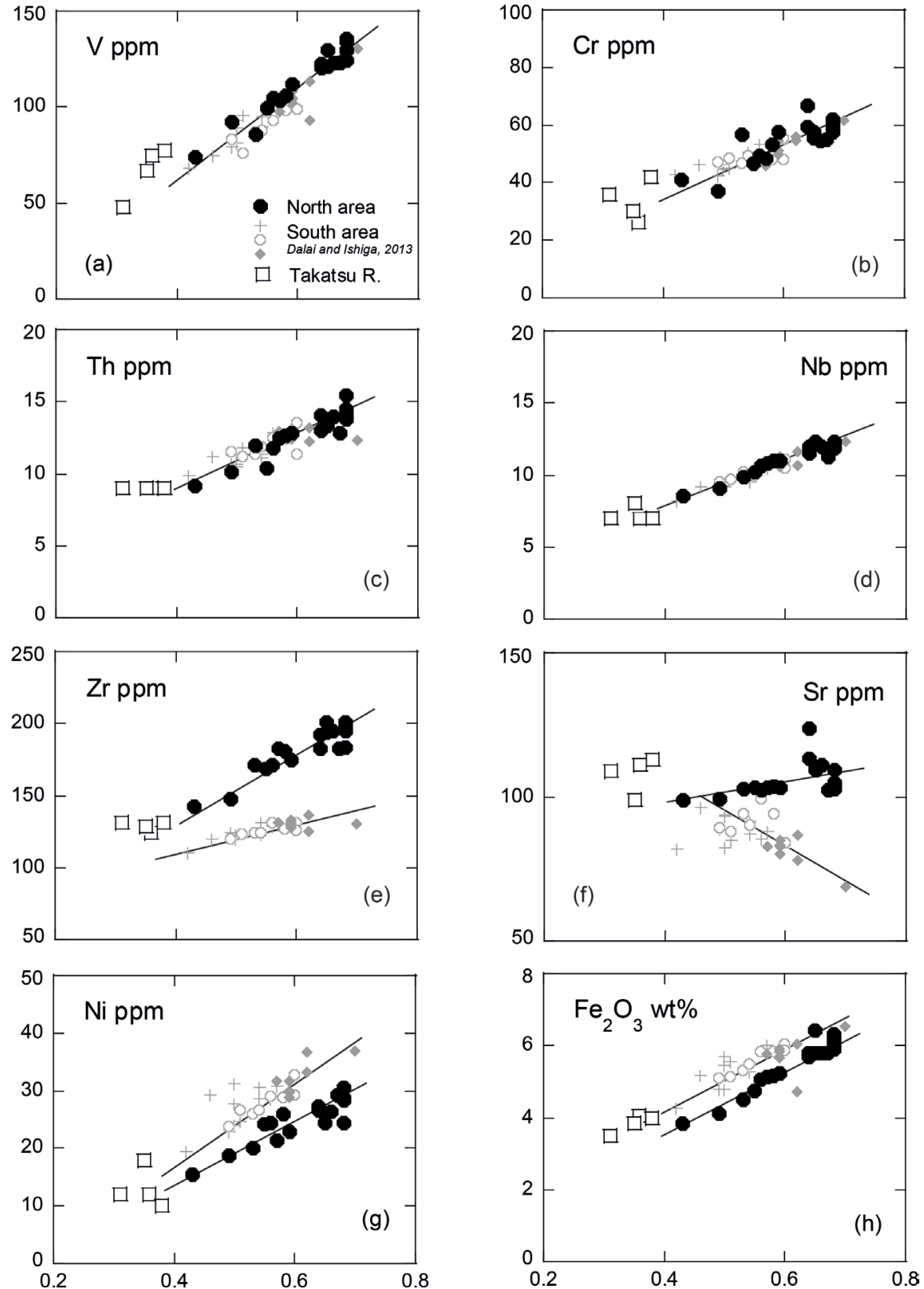

Figure 5. Elemental ratios between $\mathrm{TiO}_{2}$ and selected elements ( $\mathrm{V}, \mathrm{Cr}, \mathrm{Th}, \mathrm{Nb}, \mathrm{Zr}, \mathrm{Sr}, \mathrm{Ni}$ and $\left.\mathrm{Fe}_{2} \mathrm{O}_{3}\right)$ in archaeological floor samples. Linear lines represent the detrital trend drawn by eye 

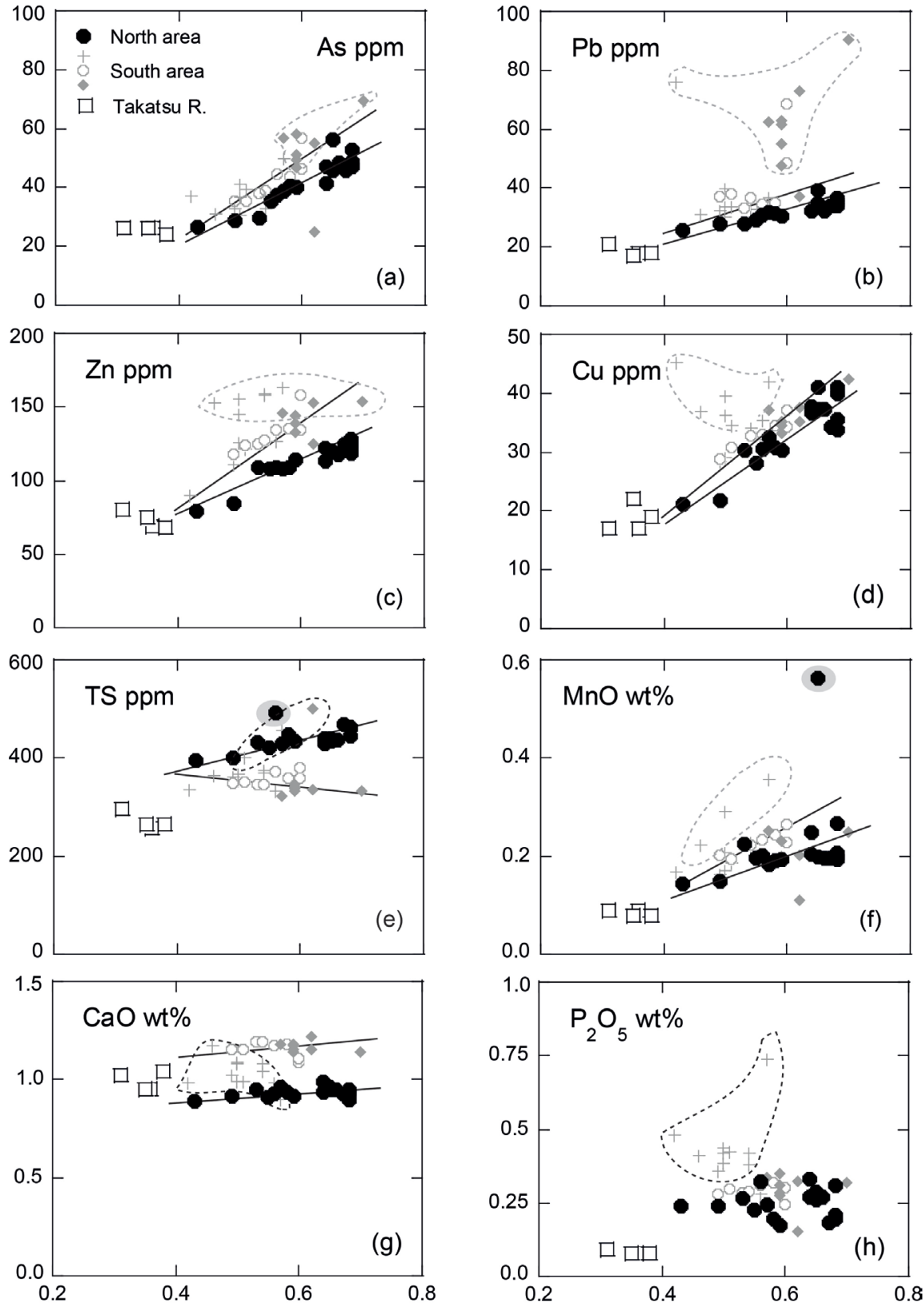

Figure 6. Elemental ratios between $\mathrm{TiO}_{2}$ and selected elements ( $\mathrm{As}, \mathrm{Pb}, \mathrm{Zn}, \mathrm{Cu}, \mathrm{TS}, \mathrm{MnO}, \mathrm{CaO}$ and $\mathrm{P}_{2} \mathrm{O}_{5}$ ) in archaeological floor samples. Linear lines represent the detrital trend drawn by eye 
However, negative or weak positive correlations exist between $\mathrm{TiO}_{2}$ and $\mathrm{MnO}$, $\mathrm{CaO}$ and $\mathrm{P}_{2} \mathrm{O}_{5}$ in the residential area, possibly due to deposition of habitation wastes (Figs. 6f, $g$ and $h$ ). Furthermore, these elements can be recognized as archaeological elements in all soil types, whether the site lithology is silt or clay. As noted above, TS and $\mathrm{Sr}$ behave similarly to $\mathrm{Zr}$ (PCA analysis; Fig. 3b). These two elements are moderately correlated with $\mathrm{TiO}_{2}$ in cross plots (Figs. 6e and 5f), indicating that they tend to reside in the silt fractions.

Zirconium is a conservative lithogenic element that is mainly contained in the resistant primary mineral zircon $[26,27,28]$. Heavy mineral enrichment is often associated with particle sorting effects due to wave action [22]. Higher concentration of $\mathrm{Zr}$ in the north area indicate coarser texture at that site relative to the south. However, these compositional differences are caused by $\mathrm{Zr}$ enrichment without significant contrast in $\mathrm{TiO}_{2}$ concentrations (Fig. 5e). The ratio between $\mathrm{Ti}$ and $\mathrm{Zr}$ is known to be a variable related to sorting and heavy mineral concentrations, as $\mathrm{Ti}$

\section{CONCLUSIONS}

Principle Component Analysis (PCA) successfully classified the archaeological floor samples in north and south areas of the harbor site, based on their geochemical variations. These compositional differences between the areas could be associated with their individual Medieval anthropogenic activities and sedimentary processes (sorting and heavy mineral concentration). Furthermore, element$\mathrm{TiO}_{2}$ ratios are useful for the evaluation of both natural and anthropogenic processes in archaeological soils, and for the identification of elemental sources or differentiation of anomalous sample populations which may have been produced by ancient human activity. Elements of anthropogenic origin tend to scatter above the basal detrital trends on the cross plots, and are enriched relative to background concentrations. Specially, samples from south area show significant elemental enrichments, is concentrated in finer minerals such as rutile and titanite, while $\mathrm{Zr}$ is relatively enriched in coarser flux such as zircon [27,28,29]. Strong positive correlations exist in the cross plot between $\mathrm{Zr}$ and $\mathrm{TiO}_{2}$ in both the north and south areas of the site. It seems both areas have been equally affected by sorting, as their range in $\mathrm{TiO}_{2}$ is similar. However, the higher trend in the north suggests that concentration of heavy minerals had occurred at that site, having a larger effect on $\mathrm{Zr}$ content than $\mathrm{TiO}_{2}$. Based on Dellwig et al. [22], our study suggests that heavy minerals may have washed out from the coastal sand dunes on the Japan Sea side by storm events during winter, and were then deposited in the northern part of the harbor site, which lay in a high energy environment. Therefore, the texture of the soils and their mineralogical compositions played important roles in the differing elemental concentration seen in the two areas of this Medieval harbor site, as did the variation of human activities. Further studies should focus on the relationship between mineralogical composition and multielement concentration of archaeological soils.

particularly for $\mathrm{As}, \mathrm{Pb}, \mathrm{Zn}, \mathrm{Cu}, \mathrm{TS}, \mathrm{MnO}, \mathrm{CaO}$ and $\mathrm{P}_{2} \mathrm{O}_{5}$ [18]. In contrast, samples from the north area of the harbor site are characterized by high concentration of $\mathrm{Zr}$, probably related to the silty nature of the soil there. However, negative or weak positive correlation also exists between $\mathrm{TiO}_{2}$ and $\mathrm{MnO}$, and $\mathrm{CaO}$ and $\mathrm{P}_{2} \mathrm{O}_{5}$ in both the areas, suggestive of deposition of habitation wastes. Those elements can be recognized as archaeological elements in all soil types, whether the site lithology is silt or clay. Another group of elements $(\mathrm{Ni}, \mathrm{Y}, \mathrm{Nb}$, $\mathrm{Zr}, \mathrm{Th}, \mathrm{TiO}_{2}$ and $\mathrm{Fe}_{2} \mathrm{O}_{3}$ ) and their ratios can be used to identify sources (provenance), as well as to establish baseline concentrations of other elements which are influenced by anthropogenic and detrital inputs. Based on archaeological features, this study describes the multi-element concentration in archaeological soils from two areas at this harbor site with 
differing soil types, in an effort to discriminate the variation of human activities. When combined with archaeological data, evidence from geochemical examination can be useful for further studies of sites elsewhere.

Acknowledgments: We are grateful to the Board of Education of Masuda City for kindly providing the opportunity of examining the
Nakazu Higashihara site, and for supplying unpublished data. We also thank the Board of Education of Masuda City for their invaluable assistance during our field work, Barry Roser and Terbishiinkhen O. Javkhlan for discussion and comment on the manuscript, and Sansfica Marlyn Young and Megumi Sakaya for sampling.

\section{REFERENCES}

1. Aston, M., Martin, M., Jackson, A., 1998. The use of heavy metal soil analysis for archaeological surveying. Chemosphere, 37(3), pp. 456-477.

2. Entwistle, J. A., Abrahams, P. W., Dodgshon, R. A., 1998. Multi-element analysis of soils from Scottish historical sites. Interpreting land-use history through the physical and geochemical analysis of soil. Journal of Archaeological Science, pp. 25, 53-68.

3. Parnell, J.J., Terry, R. E., Nelson, Z., 2002. Soil chemical analysis applied as an interpretive tool for ancient human activities in Piedras Negras, Guatemala. Journal of Archaeological Science, pp. 29, 379-404.

4. Oonk, S., Slomp, C. P., Huisman, D. J., 2009. Geochemistry as an aid in archaeological prospection and site interpretation: Current issues and research directions. Archaeological Prospection, pp. 16, 35-51.

5. Wells, E. C., Terry, R. E., Parnell, J. J., Hardin, P. J., Jackson, M. W., Houston S. D., 2000. Chemical analyses of ancient anthrosols in residential areas at Piedras Negras, Guatemala. Journal of Archaeological Science, pp. 27, 449-462.

6. Terry and Nelson, 2002.

7. Wilson, C. A., Davidson, D. A., Cresser, M. S., 2008. Multi-element soil analysis: an assessment of its potential as an aid to archaeological interpretation. Journal of Archaeological Science, pp. 35, 412-424.

8. Linderholm, J., 2007. Soil chemical surveying: A path to a deeper understanding of prehistoric sites and societies in Sweden. Geoarchaeology, pp. 4, 417-438.

9. Board of Education of Masuda City; BEMC, 2013. Nakazu Higashihara site, Report of Culture Investigation of norther part of the Masuda river bank and related buried material, Shimane Prefecture. P. 163 (in Japanese).

10. Kihara, H. (2011). Medieval harbor sites in Masuda, Iwaminokuni. Journal of the Japanese Archaeological Association, pp. 32, 181-191.

11. Ohta, Y., Matsushima, Y., Moriwaki, H., 1982. Note on the Holocene sea-level study in Japan - on the basis of "Atlas of Holocene sea-level records in Japan". Quaternary Research, pp. 21, 133-143.

12. Ohta, Y., Yonekura, N., 1987. Quaternary maps of Japan: II. Prehistoric remains and Palaeontology. Japan Association of Quaternary Research (Eds.). Tokyo University Press, Tokyo Japan.

13. Umitsu, M., 1997 Holocene sea-level changes and coastal evolution in Japan. The Quaternary Research, pp. 30, 187-196.

14. Yamada, K., 2006. Paleoenvironment of Masuda plain revealed from the geologic boring at Hamayori-Chikata archaeologic site, Japan. Report on Cultural Investigation at road Construction of Route and Masuda Road, no. 2, pp. 117-129. Ministry of Construction, Transportation and Board of Education of Shimane Prefecture. 
15. Hayashi, M., 2000 Changes of paleogeography of Masuda plain. Report on the Cultural Investigation at the medieval Imaichi Port in Masuda City, pp. 44-60. Board of Education, Masuda City (in Japanese)

16. Watanabe, M., Ishiga, H., 2008 Environmental change during the last 6400 years in the Masuda plain, western Shimane Prefecture, southwest Japan. Japan Jour. Historical Botany, pp. 16, 3-10.

17. Board of Education of Masuda City; BEMC, 2011. Nakazu Higashihara site in Masuda, Shimane Prefecture. (Report, 7 Aug 2011), p. 3 (in Japanese).

18. Dalai, B., Ishiga, H., 2013 Identification of ancient human activity using multi-element analysis of soils at a Medieval harbor site in Masuda City, Shimane Prefecture, Japan. Earth Science (Chikyu Kagaku), pp. 67, 75-86.

19. Ogasawara, M., 1987. Trace element analysis of rock samples by X-ray fluorescence spectrometry, using Rh anode tube. Bulletin of the Geological Survey of Japan, 38(2), pp/ 57-68.

20. Imai, N., Terashima, S., Itoh, S., Ando, A., 1996. 1996 compilation of analytical data on nine GSJ geochemical reference samples, "Sedimentary rock series". Geostandards Newsletter, 20, pp. 165-216.

21. Hodoki, Y., Ohbayashi, K., Minato, T., Ishiga, H., 2007. Assessment of river environments from analysis of environmental components and Ayu, Plecoglossus altivelis in the Takatsu River, Shimane, Japan. Geoscience Rept. Shimane University, 26 pp/, 1-9 (in Japanese).

22. Dellwig, O., Hinrichs, J., Hild, A., Brumsack, H.J., 2000. Changing sedimentation in tidal flat sediments of the southern North Sea from the Holocene to the present: a geochemical approach. Journal of Sea Research, 44, pp. 195-208.

23. Terry, R. E., Fernandez, F. G., Parnell, J. J., Inomata, T., 2004. The story in the floors: chemical signatures of ancient and modern Maya activities at Aguateca, Guatemala. Journal of Archaeological Science, 31, pp. 1237-1250.

24. Holliday, V. T., Gartner, W. G., 2007. Methods of soil P analysis in archaeology. Journal of Archaeological Science, 34(2), pp. 301-333.

25. Ishiga, H., Dozen, K., Sampei, Y., 1999. Geochemical constraints on marine invasion and provenance change related to the opening of the Japan Sea: an example from the Lower Miocene shales in the Hoda section, Shimane Peninsula, SW Japan. Journal of Asian Earth Sciences, 17, pp. 443-457.

26. Roser, B.P. (2000). Whole-rock geochemical studies of clastic sedimentary suites. Memoirs of the Geological Society of Japan, 57, pp. 73-89.

27. Ortiz, E., Roser, B. P., 2006. Major and trace element provenance signatures in stream sediments from the Kando River, San'in district, southwest Japan. Island Arc, 15, pp. 223 238 .

28. Ishiga, H., Nakamura, T., Sampei, Y., Tokuoka, T., Takayasu, K., 2000. Geochemical record of the Holocene Jomon transgression and human activity in coastal lagoon sediments of the San'in district, SW Japan. Global and Planetary Change, 25, pp. 223-237.

29. Taylor, S. R., McLennan, S. M. (1985). The Continental Crust: its Compositions and its Evolution. Blackwell, Oxford.

30. McLennan, S. M., Hemming, S., McDaniel, D. K., Hanson, G. N., 1993. Geochemical approaches to sedimentation, provenance and tectonics. Geological Society of America, Special paper 284, pp. 21-40.

31. Roser, B. P., Korsch, R. J. (1986) Determination of Tectonic Setting of Sandstone-Mudstone Suites Using $\mathrm{SiO}_{2}$ Content and $\mathrm{K}_{2} \mathrm{O} / \mathrm{Na}_{2} \mathrm{O}$ Ratio. The Journal of Geology, 94, pp. 635-650. 